David García Cadenas

Universidad Autónoma de Madrid

\title{
EL BLOQUE DE LOZANO EN LA TRADICIÓN DEL CABALLERO QUE ASISTE A SU PROPIO ENTIERRO: INFLUENCIA EN LA HISTORIA DE DON MIGUEL DE MAÑARA
}

Numerosos escritos han recreado en diversas etapas de la literatura española el episodio notable de la visión que un caballero tiene de su propio cortejo fúnebre. Y este simulacro de la muerte del héroe tiene invariablemente en todos los textos un fin ejemplar, proyectado para hacer recapacitar al caballero en su conducta sacrílega -por lo general el protagonista suele ser un libertino-. Asimismo, los escritos de la tradición están concebidos para adoctrinar al lector $\mathrm{u}$ oyente en la virtud cristiana, exponiendo un castigo divino en respuesta a un comportamiento pecador. Pero no todas las obras que describen este episodio presentan un mismo entramado narrativo, por el contrario se observan diferentes líneas en la concepción del argumento. Las diversas composiciones que conforman el listado de la tradición recogen, claro es, el pasaje del cortejo fúnebre, siendo éste el elemento aglutinador, y mantienen cierta similitud en la representación que se hace del mismo: a) siempre de noche, con frecuencia aquélla en que se cita el caballero con una monja; b) junto a un templo sagrado; c) comitiva fúnebre usualmente compuesta de seres sobrenaturales; d) preguntas por parte del héroe a miembros del cortejo sobre la identidad del fallecido. Pero asimismo señalamos dos grandes ramas claramente diferenciadas que afectan principalmente al desenlace del exemplum -una vez descrita ya la visión-, y a raíz de las cuales se organizan dos núcleos principales, el Bloque de Torquemada y el Bloque de Lozano. Mientras que en el primero de ellos el escrito culmina con la muerte del héroe, devorado por perros mastines ${ }^{1}$, en el segundo el personaje no fallece, sino que a partir del aviso divino vuélvese penitente y hombre de religión, amparador de los desfavorecidos. Existe, además, otro colectivo de obras que a pesar de no formar un bloque compacto como los señalados, sus escritos tienen en común que, aun describiendo el terrible acontecimiento, no constituye éste en ninguno de ellos el elemento principal o aglutinador del mismo, sino un suceso más de entre los muchos que afectan al personaje ${ }^{2}$. En estas últimas composiciones referidas, que están al margen de los dos grandes bloques citados, la visión fúnebre no es causa directa de muerte inminente o del apremiante cambio de conducta por parte del pecador (advirtiendo, asimismo, que en alguna de ellas ni siquiera hay relación entre monja y caballero).

\footnotetext{
1 Entre las composiciones que formarían parte del llamado Bloque de Torquemada citamos Jardín de flores curiosas (1570) de Antonio de Torquemada -primera obra en que aparece la tradición por escrito- el romance Castigo que hizo Nuestro Señor en un mal hombre que quiso sacar a una religiosa de su orden (1572) de Cristóbal Bravo, Luz de la fe y de la ley (1762) de Fray Jaime Barón y el romance anónimo y sin fechar cuyo título comienza Exemplar relación del manifiesto castigo que ha executado la Divina Justicia con un Cavallero. Para un mayor conocimiento del tema: David García Cadenas, Dos leyendas tradicionales de José Zorrilla: El capitán Montoya y Margarita la tornera, Tesis UAM, Madrid, 2006, pp. 291-369.

2 Respecto al siguiente colectivo señalado destacan, por ejemplo, El vaso de elección, San Pablo (1608) de Lope de Vega, El niño diablo (1631) atribuida a Vélez de Guevara, o El estudiante de Salamanca (1840) de José de Espronceda, entre títulos varios. Para un mayor conocimiento del tema: David García Cadenas, Dos leyendas tradicionales de José Zorrilla: El capitán Montoya y Margarita la tornera, Tesis UAM, Madrid, 2006, pp. 291-369.
} 
Como acabamos de señalar, el segundo gran núcleo narrativo de la tradición del propio entierro es el denominado como Bloque de Lozano. Representa este segundo grupo de textos una versión mucho más esperanzadora y positiva que la expuesta en el bloque primero o de Torquemada. Cristóbal Lozano hará en su obra Soledades de la vida y desengaños del mundo ${ }^{3}$ (1658) una versión muy relevante del episodio escrito por primera vez en la miscelánea El jardín de flores curiosas ${ }^{4}$, y cambiará su desenlace cruel por un final mucho más optimista y alentador. Se trata de una adaptación que ejercerá enorme influencia en la literatura posterior, y cuyas variaciones respecto al episodio tipo que desciende de Torquemada obtendrán un seguimiento mayor, hasta el punto de absorber bajo sus nuevos aspectos la mayor parte de los textos subsiguientes. 5 . Incluso su enorme notoriedad contaminará tradiciones o leyendas vecinas, ya que caballeros como don Miguel de Mañara o el propio don Juan Tenorio -como veremos- acabarán finalmente presenciando su propio entierro (por contagio suyo).

Soledades de la vida y desengaños del mundo es una amalgama de historias y cuentos engarzados en una trama principal. Al argumento base, que es la relación amorosa entre Lisardo y Teodora, se une una serie de relatos menores que se relacionan finalmente con él, debido a que son incidentes ocurridos a determinados personajes que se cruzan en la vida de los amantes. El libro está dividido en cuatro partes o soledades; el episodio del entierro estaría incluido en la última de las cuatro, siendo el suceso más importante y significativo de la obra. El estudiante Lisardo es un hombre temeroso de Dios y durante el desarrollo de la trama dará amplias muestras de su religiosidad, aspecto que será fundamental para su salvación. Detalles cristianos tan considerados como la manera de acceder al templo sagrado la noche de la pretendida fuga (se quita el sombrero, toma agua bendita, persígnase e hinca sus rodillas ante el altar), el temor que provoca en su ánimo la propuesta de la monja de escaparse juntos, y el hecho de que el motivo principal de la fuga sea el matrimonio con Teodora y no la búsqueda exclusiva del goce carnal -a diferencia de las intenciones pecaminosas que rodeaban al caballero anónimo del Bloque de Torquemada-, son elementos que no desmerecen a los ojos de Dios, y que argumentan a favor de una segunda oportunidad. Pero por encima de todos estos detalles citados aquél que notoriamente origina el aviso y posibilidad de perdón es el de las numerosas oraciones que dedicó en vida a las sufrientes almas del purgatorio, razón por la cual es celebrada una ceremonia fúnebre para su salvación. Ésta es, en definitiva, la novedad más notable que el texto de Lozano incorpora a la tradición, y que es el argumento religioso principal del libro. La comitiva del entierro no está formada por cualesquiera fantasmas sin un fin concreto, está compuesta por ánimas del purgatorio que hacen las exequias para Lisardo, cuya alma está a punto de condenarse. Estas misas oficiadas en honor del estudiante lo son en pago

3 Cristóbal Lozano, Soledades de la vida y desengaños del mundo, facsímil de la edición de 1663, Instituto de Estudios Albacetenses Don Juan Manuel, Albacete, 1998.

4 Antonio de Torquemada, Obras completas I, «Manual de escribientes», «Coloquios satíricos», «Jardín de flores curiosas», Biblioteca Castro-Turner, Madrid, 1994, pp. 684-687. Historia de amor entre un caballero laico y una monja. La noche en que se citan para pecar sucede un hecho extraordinario, ocurre que el galán sufre la visión de su propio entierro y huye despavorido del lugar, todo ello antes de gozar de la compañía de la religiosa. Ya en el camino de regreso hacia su casa, este caballero padece el acoso de dos grandes mastines. Finalmente, y una vez que consigue llegar al hogar, los dos perros gigantescos acaban con su vida.

5 Sólo el fragmento de Fray Jaime Barón, Luz de la fe y de la ley del año 1762 -y, por tanto, posterior al texto de Cristóbal Lozano de 1658- se mantiene totalmente al margen de la influencia ejercida por el libro Soledades de la vida... . 
a las oraciones y limosnas que les dedicara el caballero durante toda su vida, y que en agradecimiento intentan salvar ahora su alma, que se condena irremisiblemente. Es la primera vez que el concepto ánimas del purgatorio aparece en esta tradición. Su presencia en la historia habla nuevamente a favor de las indulgencias y demás consideraciones religiosas que inciden en la salvación de las almas, advirtiendo una lectura propia de la Contrarreforma, donde el hombre gracias a su libre comportamiento puede conseguir la misericordia divina, y todo depende del arrepentimiento sincero en su conducta última.

Caballero, todos los que estamos presentes somos almas, que ayudadas con las oraciones y limosnas de Lisardo salimos del purgatorio, a cuyo favor reconocidas venimos a enterrarle, y a hacer por él aquellas exequias, porque está su alma en duda de salvación. (Lozano, 1998: 168-169) ${ }^{6}$

En Soledades de la vida... se describen dos incidentes insólitos relacionados con la muerte del estudiante. Si uno de ellos es la visión del propio entierro, antes de él se narra otro suceso que tiene consecuencia directa con la ceremonia fúnebre: la noche de la fuga el caballero creerá divisar, mientras permanecía oculto, su propio asesinato. El aviso divino de este texto comprende entonces un mayor recorrido -son en realidad dos movimientos o fases- pues hay que incorporar a la visión del entierro este segundo incidente junto a las calles del templo, donde un caballero llamado Lisardo perece acuchillado, inconfeso y en pecado mortal (como consecuencia del terrible pecado que tenía en mente llevar a cabo). La lectura global del mensaje divino una vez conjugados ambos incidentes sería que si el caballero no es consciente de lo que aquella ceremonia fúnebre implica y no se arrepiente de la pecadora empresa que estaba dispuesto a realizar morirá tal cual tuvo la oportunidad de presenciar. Aquel suceso que observara oculto tras unos costales es un anuncio de lo que le va a pasar -muerte física y condenación eterna de su alma- si insiste en su propósito. La prueba más clara de todo ello se demuestra cuando se informa al lector que muere a cuchilladas, y de forma muy parecida a como presenciara Lisardo junto a las calles del templo, un pobre peregrino con quien el estudiante cambia sus ropas momentos después de haber presenciado las misas y dedicarse a la religión. Se libra de la muerte, así pues, porque su arrepentimiento ha ocasionado que cambiara sus prendas de caballero por las de un peregrino, el cual será quien reciba las cuchilladas hacia Lisardo dirigidas.

La verdadera finalidad de la obra y su lectura primera es precisamente el arrepentimiento definitivo del héroe, razón por la cual se mantiene con vida. Ése es el aspecto diferenciador respecto al otro Bloque de Torquemada donde la muerte física del caballero era inflexible así como la posible condenación de su alma. Lisardo, tras presenciar la misa sufre un desfallecimiento. Una vez recuperado su comportamiento variará decisivamente, y consciente de todo lo que le ha sucedido abandonará la idea de reunirse con la monja dedicando el resto de su vida a hacerse grato a los ojos de Dios (repartirá asimismo sus riquezas entre los criados). El desmayo del héroe no sólo debemos interpretarlo como un vahído producto de un ataque de nervios, sino que, básicamente, simbolizará la muerte de Lisardo, y el nacimiento de un nuevo hombre de Dios, de un penitente. El recurso del desmayo constituye el final de una vida y el comienzo de otra muy distinta, totalmente virtuosa. Cuando el caballero regresa a su casa, ya totalmente cambiado como producto de la visión del entierro, le dirigirá a su criado Camacho las siguientes palabras:

${ }^{6}$ Soledades de la vida..., pp. 168-169. 
Quédate con Dios, que ya es muerto Lisardo, yo propio le vi matar, yo propio acompañé su entierro, yo propio he asistido a sus exequias. Ya no hay Lisardo Camacho amigo, ya desde ahora no me verá más tus ojos; ya para salvarme me parto a hacer penitencias. (Lozano, 1998: 169-170) ${ }^{7}$

Mucho más célebre se hizo la conseja de la visión del propio entierro a partir de esta novela de Cristóbal Lozano, circunstancia que provocó que la base argumentativa de esta tradición se identificara principalmente con los sucesos que protagoniza en ella Lisardo, suponiendo el gran referente desde entonces del episodio del entierro. La visión fúnebre estaba ahora ligada, sobre todo, a las aventuras del estudiante cordobés, y no así a la del caballero anónimo mordido cruelmente por sendos mastines. Se hicieron tan conocidos los incidentes que, según escribiera Agustín Durán: «apenas había un español que no la supiese de memoria, y que no se apoderase de ella para leerla en el libro o en los romances.» ${ }^{8}$ Efectivamente, al poco tiempo salieron en pliego suelto dos romances anónimos sobre el mismo personaje, Lisardo el estudiante de Córdoba, que reproducían en verso el mismo episodio de Soledades de la vida... El Bloque de Lozano empezaba, pues, a formarse y lo hacía de acuerdo a las siguientes características, diferentes al Bloque de Torquemada:

1) El héroe tendrá nombre propio, no se le tratará de forma anónima.

2) Prevalece un desenlace positivo ya que el caballero, totalmente arrepentido de su idea pecadora, terminará haciendo penitencia.

3) Las misas son oficiadas por ánimas del purgatorio y una vez escuchadas el protagonista sufre un desmayo que simboliza la muerte del caballero pecador y el nacimiento del caballero virtuoso.

Ajustados a estos tres puntos se articularán toda una serie de obras posteriores relativas a la tradición del entierro. Sin fechar ${ }^{9}$ y escritos por autor anónimo (como hemos señalado arriba), fueron recogidos en un pliego en dos partes, incorporados en 1821 por Agustín Durán en su Romancero general $^{10}$, dos composiciones que versifican el episodio de Soledades de la vida... Son dos romances que desarrollan nuevamente la historia de amor entre el estudiante Lisardo y la monja Teodora, recogiéndose sólo en el segundo de ellos el episodio del entierro, y ya con la incorporación de los nuevos aspectos que introdujera Cristóbal Lozano (versificará incluso el suceso previo en que el héroe contempla su asesinato). En estos romances se advierte un mayor interés en mostrar al joven caballero como un torpe conquistador, muy poco experimentado en lances amorosos. El personaje Lisardo -tanto en la novela como principalmente en las poesías- es retraído y respetuoso, para nada se muestra mujeriego ni reñidor.

\footnotetext{
7 Ibidem, pp. 169-170.

8 Agustín Durán, Romancero general o colección de romances castellanos anteriores al siglo XVIII, tomo II, Biblioteca de Autores Españoles, XVI, Madrid, 1945, p. 266.

9 Según Francisco Mendoza Díaz-Maroto en su edición de Soledades de la vida y desengaños del mundo, Instituto de Estudios Albacetenses Don Juan Manuel, Albacete, 1998, p. XXX, los romances serían de la primera mitad del siglo XVIII.

${ }^{10}$ Agustín Durán, Romancero general o colección de romances castellanos anteriores al siglo XVIII, tomo II, Biblioteca de Autores Españoles, XVI, Madrid, 1945, romances 1271 y 1272.
} 
La celebridad de estos romances fue extraordinaria. La fama del estudiante Lisardo se debió principalmente a estos versos que, actuando como mera selección, habían versificado exclusivamente el suceso sobrecogedor del entierro, olvidando el resto de la novela, que interesaba menos al público oyente. La popularidad del episodio llegó a ser tal que los romances vieron en tiempos posteriores nuevas ediciones. Tanto es así que, impresos en Madrid en 1848, aparecen otros dos poemas bajo el siguiente título Nueva relación en que se declara los lances de amor, miedos y sobresaltos que acaecieron a este caballero, natural de la ciudad de Córdoba, y a doña Teodora, de la de Salamanca ${ }^{11}$, cuyo texto es prácticamente idéntico a las dos composiciones recogidas por Agustín Durán en su Romancero general. Asimismo la novela tuvo en el mismo siglo XVIII una refundición bajo el título Historia de Lisardo el Estudiante de Córdoba, y de la hermosa Teodora, con los trágicos sucesos del ermitaño Enrico ${ }^{12}$. De principios del siglo XIX encontramos también un folleto que la resume en prosa ${ }^{13}$.

Pero de la celebridad de esta novela y de los dos romances no sólo son muestra las ediciones posteriores que arriba apuntamos, el más claro indicador de su popularidad es la influencia que ejerció en otro tipo de narraciones. Curiosamente este héroe de nombre Lisardo, tan alejado del canon previsible del seductor, contaminará la leyenda del galán don Miguel de Mañara, personaje real que vivió en Sevilla desde 1627 hasta 1679, año en que murió, y que fue muy conocido por haber fundado el Hospital de la Santa Caridad en la citada ciudad andaluza. Se creó una leyenda popular en torno a la figura de este sevillano, cuya vida activa coincidió con la etapa de impresión y mayor fama del caballero ficticio Lisardo. Don Miguel de Mañara, como también el personaje literario que creara Cristóbal Lozano, culminará su vida como un penitente, dedicado a la vida religiosa y ayudando a los más desfavorecidos. Será ese perfil de santidad coincidente en ambos personajes aquello que acabará relacionando las dos leyendas. El padre jesuita Juan de Cárdenas publicó en 1680, un año después de la muerte del caballero, una Breve relación de la muerte, vida y virtudes del venerable caballero don Miguel de Mañara Vicentelo de Leca $^{14}$. El libro del jesuita recogía básicamente la vida del sevillano en el monasterio, elogiaba tanto su ayuda a los más necesitados como su total dedicación a la obra de Dios. Además informaba de algunos momentos previos a su vida monacal, y entre ellos citaba Juan de Cárdenas un curioso suceso que de alguna manera pudiera relacionarse con aquella extraña muerte que presenciara Lisardo junto a las calles del convento:

En su mocedad, antes que se hubiera recogido a vida ajustada, le sucedió que, yendo una noche por la calle del Ataúd, en esta ciudad de Sevilla, sintió que le dieron un golpe en el cerebro, tan recio, que lo derribó en tierra, y al mismo punto oyó una voz que dijo: «Traigan el ataúd, que ya está muerto» Levantóse turbado y fuera de sí, con que no se atrevió a proseguir su camino y volvió atrás, y después supo que en la casa adonde iba

\footnotetext{
${ }^{11}$ Han sido publicados por Luis Estepa, La colección madrileña de romances de ciego que perteneció a don Luis Usoz y Río, estudio por Luis Estepa, Biblioteca Básica Madrileña, Madrid, 1995-1998, pp. 457-464.

12 Joaquín de Entrambasaguas, El doctor don Cristóbal Lozano, Revista de Archivos, Bibliotecas y Museos, Madrid, 1927, p. 62.

${ }^{13}$ Tomado de la introducción a Soledades de la vida... ya mencionada de Francisco Mendoza Díaz-Maroto (nota 22), p. XXX.

${ }^{14}$ Juan de Cárdenas, Breve relación de la muerte, vida y virtudes del venerable caballero don Miguel de Mañara Vicentelo de Leca, G. Álvarez y C ${ }^{\mathrm{a}}$ impresores, Sevilla, 1874.
} 
estaban aguardándole para matarle; con que reconoció que el golpe había sido de la mano de Dios y que el aviso había sido del Cielo, y uno y otro ordenándolo la Providencia divina para librarlo de la muerte que infaliblemente le aguardaba. (Cárdenas, 1874: 53) ${ }^{15}$

Este acontecimiento no supuso la inmediata redención de don Miguel de Mañara, no obstante -y como acabamos de señalar- el claro parecido que posee con la pseudomuerte de Lisardo supone un primer paso coincidente con el Bloque de Lozano y pudiera presagiarse la continuación de la historia con la consecuente visión del propio entierro por parte del noble sevillano, como le sucede al estudiante cordobés; sin embargo este episodio se encuentra ausente por completo en el escrito del jesuita. Según la biografía del padre Cárdenas fueron numerosas las llamadas a la religión, y al parecer será la muerte prematura de su amada esposa la única razón que le indujo definitivamente a ello. Incluido en el libro de Juan de Cárdenas se encontraba a su vez el Testamento del venerable caballero don Miguel de Mañara. En este comunicado, escrito por el propio aristócrata andaluz, advertimos una sucesión de detalles que recrean la imagen del caballero como la de un joven disoluto -muy lejos, sin embargo, de lo que pudiera pensarse tras conocer su historia legendaria-, de lo que se arrepiente y queja con cierta amargura. Y es la inscripción que manda grabar en su losa el aspecto principal que va a alimentar el mito de Miguel de Mañara como el de un burlador arrepentido: «Y es mi voluntad se ponga encima de mi sepultura una losa de media vara en cuadro, escritas en ella estas palabras: Aquí yacen los huesos y cenizas del peor hombre que ha habido en el mundo. Rueguen a Dios por él.» ${ }^{16}$ Tanto en la biografía de Juan de Cárdenas como en su testamento no hay tal abundancia de vilezas que puedan forjar sobre la persona de Mañara una historia semejante a la que ha transcendido, por ello pensamos que es la imaginación popular construida principalmente en torno a la inscripción quien ha encumbrado la leyenda.

Pero ¿qué fue aquello que originó la conversión de tan pecador caballero? En el esclarecimiento de este detalle tendrá lugar la conexión con nuestra tradición, es decir, con la visión del propio entierro. Tanto Lisardo como Mañara sufrieron ambos un repentino cambio en su conducta pecadora, y resulta entonces probable pensar que el motivo del súbito arrepentimiento de don Miguel de Mañara se buscara intuitivamente en esta otra tradición popular, identificándose así con Lisardo, leyenda pareja en su positiva doctrina y que gozaba entonces de gran notoriedad. Se debía explicar de alguna manera aquella repentina conversión, buscar explicación al hecho de que el pecador sevillano se transformara inesperadamente en un hombre de Dios; y advirtiendo tanto la contemporaneidad de ambos mitos como la correspondencia temática que se establece entre ellos, no era extraño que se originara una identificación bastante elemental entre los personajes, y todo ello a pesar de que Lozano no era un burlador. Si la conversión por parte de Mañara sabemos - por el libro de Juan de Cárdenas- que se debió a la muerte de su mujer, también advertimos que esta versión no se asentó entre la opinión popular, y ello como consecuencia de que entraríamos en una incongruencia muy simple: si en el pueblo ha germinado la leyenda del caballero sevillano como la de un vividor, cómo entonces admitir que su mudanza fue originada por la muerte de su muy querida esposa. La conexión entre las leyendas de Lisardo y Mañara resultaría, así pues, perfectamente admisible: Mañara sería el caballero disoluto e inmoral -de acuerdo a la inscripción en su tumba- que, de mane-

\footnotetext{
15 Ibidem, p. 53.

${ }^{16}$ Ibidem, p. 119.
} 
ra repentina, escucha la llamada de Dios y se convierte en un monje virtuoso que se dedica a ayudar a los pobres. La tradición de Lisardo influiría de esta suerte en la leyenda de Mañara aportándole un argumento básico en su concepción: rellenaría el hueco de su conversión inesperada. Es entonces cuando, contaminado por la historia de Lisardo -ayudado también por ese episodio previo en que cree contemplar su asesinato, presente en las dos relaciones- la transformación repentina estaría generada por un suceso de verdadero impacto: la visión del propio entierro con que el cielo le indica que si no endereza su vida se condenará en el infierno. De esta manera se ha buscado en una tradición cercana la causa directa del proceder repentino del caballero, supliendo así el posible vacío que existiera en el hecho de haber cambiado en una sola noche toda una vida. La razón por la cual dejara su existencia de maldades tiene ahora como excusa un acontecimiento realmente sugerente. A partir de entonces el episodio del entierro permanecerá unido a la leyenda del sevillano redimido, y muchas obras que recrean la vida de don Miguel de Mañara introducirán entre sus contingencias la visión terrible del propio funeral. ${ }^{17}$

El artífice primero que fusionó estas dos historias fue el autor francés Prosper Mérimée en la novela corta de 1834 Las Ánimas del Purgatorio ${ }^{18}$. En ella el protagonista se llamará don Juan de Marana, detalle interesante porque, aunque cambie ligeramente el apellido (Mañara-Marana), la referencia al noble sevillano es incuestionable; y asimismo por el hecho de utilizar el nombre de don Juan (en vez de don Miguel), con toda la carga significativa que ello conlleva desde una concepción literaria, viéndose -por endesubrayadas en el personaje las dotes de conquistador y burlador de mujeres propias del nuevo nombre heredado. Mérimée recrea su historia a partir del episodio impreso en Soledades de la vida... y su novela será un texto más dentro de los escritos que conforman la tradición del entierro: vemos así, nuevamente, la historia de amor entre galán y monja, o las preguntas habituales a los espectros que forman el cortejo. Asimismo posee características propias del Bloque de Lozano que muestra inequívocamente su clara ascendencia: por ejemplo son de nuevo las ánimas del purgatorio quienes rezan a favor del alma del héroe, volvemos a encontrar el desfallecimiento posterior, y asistimos también a un final positivo con la conversión del pecador. Además, y como apunte adicional, señalamos que de la misma manera que ocurriera con Lisardo en la obra de Lozano, aquellos mismos lances tienen también lugar en las calles de Salamanca. Pero existe sobre todo un detalle en la novela de Mérimée que es muestra directa de la presencia del mito de Mañara, y que, por consiguiente, no había aparecido hasta entonces en texto alguno de la tradición. Al final de la obra se hace referencia a una inscripción que el personaje mandó grabar en su tumba, tal cual se indica en el Testamento del venerable caballero don

${ }^{17}$ Incluso en la actualidad el episodio que estudiamos de la visión del entierro está presente en la tradición de don Miguel de Mañara. Prueba de ello lo tenemos en una guía turística sevillana Conocer Sevilla, en cuya página web (www.artesacro.org/conocersevilla/templos/iglesias/sanjorge) aparece la siguiente información escrita por José Alfonso Muriel:

Justo enfrente de este monumento hay una lápida que narra un intento de asesinato confabulado contra Mañara. Parece ser que al final hay una confusión y muere otra persona. Cuando Mañara llega al lugar citado se encontró con la mortuoria que estaba sacando el cuerpo envuelto en una sábana. Preguntó de quién se trataba y le respondieron que el muerto era Don Miguel de Mañara....... a partir de entonces comienza Mañara a pensar que hay algo sobrenatural en todo esto.....

${ }^{18}$ Prosper Mérimée, Las Ánimas del Purgatorio, La Venus de Ille, Carmen, Lokis, traducción de María Badiola Dorronsoro, Gredos, Madrid, 2003, pp. 35-111. 
Miguel de Mañara: «En su lecho de muerte, pidió la gracia de que lo enterrasen en el umbral de la iglesia, para que todo el que entrara lo pisoteara. Quiso que en su tumba grabaran esta inscripción: Aquí yace el peor hombre que fue en el mundo.» ${ }^{19}$

Por todo ello, observamos que el propósito de Mérimée en 1834 fue el de escribir una nueva versión del estudiante Lisardo (muy conocido, como sabemos, desde el siglo XVI) añadiendo características del personaje real don Miguel de Mañara, cuya leyenda era muy popular en Sevilla. La carga argumentativa respondía nuevamente al Bloque de Lozano, desarrollándose una versión pareja al libro de Soledades de la vida... Y si el entramado del texto se ajustaba totalmente al esqueleto de la tradición del entierro, y no a la historia de Mañara -su presencia en esta leyenda sevillana se muestra sólo al final, en que se hacen referencias continuas a la vida religiosa del personaje- sin embargo el nombre dado al héroe se correspondía con el del sevillano y no con el del estudiante cordobés, consiguiendo con ello que la historia del entierro se adhiriera y articulara deliberadamente con las aventuras del fundador del Hospital de la Caridad (edificio del que se hace también mención al final del texto). Y todavía mayor será la identificación entre los dos personajes citados cuando en 1851 José Gutiérrez de la Vega publique en el Semanario pintoresco español un escrito titulado Don Miguel de Mañara ${ }^{20}$. En él se describe la vida disipada del joven noble sevillano y su súbita conversión, de nuevo producida tras presenciar la comitiva fúnebre. Sin embargo no hay aspecto alguno en la narración que haga referencia a la tradición del entierro salvo la visión de éste. Todo el escrito es una recreación casi exclusiva de la leyenda de Mañara, incluido por fin el nombre correcto del personaje, al que se le añade el cortejo fúnebre, como si definitivamente ya hubiese sido absorbido y formara parte inalterable de la misma. Lo que se describe en la historia son, principalmente, aspectos de la leyenda sevillana -la calle del Ataúd, la estocada en la cabeza, las palabras que escucha acerca de su presumible muerte, la fundación del Hospital de la Caridad- presentes todos ellos en la biografía escrita por el jesuita Cárdenas y en el testamento del propio Mañara. Así pues, mientras la novela de Mérimée era una versión más del personaje de Lisardo, el breve escrito de Gutiérrez de la Vega lo es de Mañara, pero en ambos el episodio culminante es la visión del entierro, confundiendo y conjuntando ambas historias. ${ }^{21}$

Pero en ese listado de títulos relacionados con el Bloque de Lozano, entendiendo con ello tanto las contingencias del personaje Lisardo como su consiguiente asociación con las aventuras de don Miguel de Mañara, hemos dejado sin señalar la leyenda en verso de José Zorrilla titulada El capitán Montoya ${ }^{22}$ (1840), que vuelve a ser un claro exponente de esa mezcolanza y confusión presente entre las dos historias. Como ocurriera con la novela corta Las Ánimas del Purgatorio escrita en 1834, la composición de Zorrilla es un escrito que se ajusta a las características de la tradición del entierro, siguiendo el llama-

\footnotetext{
${ }^{19}$ Ibidem, p. 110

20 José Gutiérrez de la Vega, «Don Miguel de Mañara», en Semanario pintoresco español, n` 52, Madrid, 1851, pp. $410-412$.

${ }^{21}$ El personaje de don Miguel de Mañara tendrá una amplia descendencia, ya presentando o no como causa de la conversión del héroe la visión terrible del sepelio. Muchas obras trataron la leyenda del caballero sevillano después de este último relato de Gutiérrez de la Vega. Daremos a continuación la lista de algunas obras que la han desarrollado en España: Tradición sevillana, Manuel Cano y Cueto; Juan de Mañara, Antonio y Manuel Machado; Miguel de Mañara, Manuel Fernández y González; La conversión de Mañara, Joaquín Dicenta.

22 José Zorrilla, Leyendas, edición de Salvador García Castañeda, Cátedra, Madrid, 2000, pp. 158-210.
} 
do Bloque de Lozano, pero a cuyo argumento sabido se incorporan toda una serie de rasgos específicos que responden directamente a la historia de don Miguel de Mañara, formando parte de esos escritos híbridos que tienen como modelo la citada obra de Mérimée, fuente primera de esa unión. La presencia de esta novela corta francesa en El capitán Montoya de José Zorrilla es muy considerable, y advertimos varios detalles exclusivos de Las Ánimas del Purgatorio incorporados por el autor de Valladolid en su leyenda:

1) El cambio de nombre del héroe una vez recuperado del desmayo; simbolizando que un nuevo hombre requiere una nueva identidad.

2) Provocación e insultos por parte de los familiares de las víctimas hacia el caballero una vez que éste abandona su vida frívola. ${ }^{23}$

3) La inscripción en la tumba; que Mérimée fue el primero en utilizar.

Pero si hemos señalado El capitán Montoya como un texto de especial interés en la tradición del entierro no es, sin embargo, por su carácter de híbrido -uno más de entre los muchos escritos que ya hemos referido-, sino por el paso previo que supone respecto a la inmortal obra de Zorrilla Don Juan Tenorio (1844). El propio autor citará en la Nota que prologaba esta leyenda para la edición de sus Obras completas (1884) que la obra no era más «que un embrión del $D$. Juan» $»^{24}$. Son muchos los aspectos comunes en que ambas composiciones concurren, ya sea el prototipo de donjuán o conquistador, ya la presencia de una monja seducida por el galán, ya la apuesta por parte del caballero de lograr seducir una religiosa; pero, sobre todo, observamos como una influencia más de la leyenda $E l$ capitán Montoya que en el drama de 1844 el burlador sevillano presencie también el cortejo de su propio funeral. Es así como el episodio terrible del simulacro macabro llega a formar parte del universo literario de don Juan Tenorio. En la parte II, acto III, escena II del drama de José Zorrilla, la figura pétrea de don Gonzalo informa al galán que las campanas que doblan a muerto son las de su expiración, debido a que fue matado por el capitán. Acto seguido don Juan ve pasar su entierro y escucha las oraciones fúnebres; sin embargo no preguntará a los miembros de la comitiva -los cuales tampoco serán descritos-, ni se acercará al cadáver para cerciorarse de que es él el fallecido. Su comportamiento es mucho más relajado, y a la escena no se le dedica una extensión semejante.

$\begin{array}{ll}\text { DON JUAN: } & \text { ¿Y esos cantos funerales? } \\ \text { ESTATUA: } & \begin{array}{l}\text { Los salmos penitenciales, } \\ \text { que están cantando por ti. }\end{array} \\ \text { DON JUAN: } & \text { ¿Y aquel entierro que pasa? } \\ \text { ESTATUA: } & \text { Es el tuyo. } \\ \text { DON JUAN: } & \text { ¡Muerto yo! } \\ \text { ESTATUA: } & \begin{array}{l}\text { El capitán te mató } \\ \text { a la puerta de tu casa. (Zorrilla, 1943: 1317) }\end{array}\end{array}$

\footnotetext{
${ }^{23}$ En el apartado IX de la leyenda de Zorrilla El capitán Montoya, el padre de Diana insultará y humillará al capitán con el fin de provocarle y poder limpiar su honor. La misma situación se describe al final de la novela Las ánimas del Purgatorio de Mérimée, como también en la escena VI, jornada V de Don Álvaro y la fuerza del sino del Duque de Rivas. Para la relación citada entre esta escena presente en Mérimée y el Duque de Rivas consultar Juan Luis Alborg, en Historia de la literatura española, tomo IV, Gredos, Madrid, 1980, pp. 482-483

${ }^{24}$ José Zorrilla, Obras completas I, edición de Narciso Alonso Cortés, Librería Santarén, Valladolid, 1943, p. 2.203.

${ }^{25}$ Ibidem, II, p. 1.317.
} 
De tal manera que la tradición del entierro, aparecida primeramente en el Jardín de flores de curiosas (1570) escrita por Antonio de Torquemada, no sólo va a contagiar e influenciar la leyenda de don Miguel de Mañara - a partir de la versión que de ella hiciera Cristóbal Lozano- sino que también acabará siendo una aventura más del galán sevillano don Juan Tenorio según la versión de José Zorrilla, la más popular de cuantas se han creado. Sin embargo el episodio no supone una piedra angular en Don Juan Tenorio, y a diferencia de los escritos que integran los bloques de Torquemada y Lozano, este incidente no es el más representativo del escrito, siendo que, a diferencia de los citados, la construcción del drama no se concibe alrededor de este suceso.

\section{BIBLIOGRAFÍA}

Cárdenas, J. de (1874): Breve relación de la muerte, vida y virtudes del venerable caballero don Miguel de Mañara Vicentelo de Leca. Sevilla: G. Álvarez y Ca impresores.

Duque de Rivas (1993): Don Álvaro o La fuerza del sino. Donald L. Shaw (ed.). Madrid: Castalia. Durán, A. (1945): Romancero general o colección de romances castellanos anteriores al siglo XVIII, tomo II. Madrid: Biblioteca de Autores Españoles.

Entrambasaguas, J. de (1927): El doctor don Cristóbal Lozano. Madrid: Revista de Archivos, Bibliotecas y Museos.

Estepa, L. (1998): La colección madrileña de romances de ciego ciego que perteneció a don Luis Usoz y Río. Madrid: Biblioteca Básica Madrileña.

García Cadenas, D. (2006): Dos leyendas tradicionales de José Zorrilla: El capitán Montoya y Margarita la Tornera. Madrid: Tesis UAM.

Gutiérrez de la Vega, J. (1851): «Don Miguel de Mañara». En Semanario pintoresco español, 52, 410-412.

Lozano, C. (1998): Soledades de la vida y desengaños del mundo. Francisco Mendoza Díaz-Maroto (ed.). Albacete: Instituto de Estudios Albacetenses Don Juan Manuel.

Merimée, P. (2003): Las Ánimas del Purgatorio, La Venus de Ille, Carmen, Lokis. María Badiola Dorronsoro (ed.). Madrid: Gredos.

Torquemada, A. de (1994): Obras completas. Madrid: Biblioteca Castro-Turner.

Zorrilla, J. (1943): Obras completas. Narciso Alonso Cortés (ed.). Valladolid: Librería Santarén.

Zorrilla, J. (2000): Leyendas. Salvador García Castañeda (ed.). Madrid: Cátedra. 


\section{LOZANOV BLOK V IZROČILU MOŽA, KI PRISOSTVUJE LASTNEMU POGREBU: NJEGOV VPLIV NA ZGODBO O DON MIGUELU DE MAÑARI}

Po zgledu knjige Jardín de flores curiosas (1570) Antonia de Torquemade je nastalo veliko del, ki so kot jedro uporabila eno od epizod - tisto o možu, ki prisostvuje svojemu pogrebu, in tako se je oblikovala tema z razvejeno prisotnostjo v španski književnosti. Med mnogimi besedili, ki so pozneje razvijala ta dogodek, izstopa Soledades de la vida $y$ desengaños del mundo (1658), Cristóbala Lozane. Njegova različica priredi razplet izvirne epizode tako, da predstavi veliko bolj optimistično videnje božjega opozorila. V izvirnem Torquemadovem odlomku junaka požrejo mastifi, v Lozanovi zgodbi pa se mož poglobi vase in preostanek življenja povsem preda veri. Besedila, ki so sledila tej bolj spodbudni in pozitivni različici legende, se uvrščajo v t. i. Lozanov blok (Bloque de Lozano), medtem ko se prejšnja skupina imenuje Torquemadov blok (Bloque de Torquemada). Zaradi priljubljenosti nove priredbe, ki jo je vpeljal Lozano, članek analizira tudi vpliv te legende na pomembne like, kot sta Miguel de Mañara in don Juan Tenorio. 